\title{
Finnish flies of the family Therevidae
}

\author{
Antti Haarto \& Kaj Winqvist
}

Haarto, A. \& Winqvist, K. 2006: Finnish flies of the family Therevidae. — Entomol. Fennica 17: 46-55.

An illustrated key for the 17 Finnish species of Therevidae is presented that includes six species recorded from neighbouring areas. Distributions of the Finnish species are discussed and presented in maps; evaluations concerning the threatenedness status of Finnish species are included.

Antti Haarto, Zoological Museum, Section of Biodiversity and Environmental Science, University of Turku, FI-20014 Turku, Finland; E-mail: antti.haarto @.turkuamk.fi

Kaj Winqvist, Zoological Museum, University of Turku, FI-20014 Turku, Finland; E-mail:kwinqvist@hotmail.com

Received 31 January 2005, accepted 13 July 2005

\section{Introduction}

Flies of the family Therevidae belong to the suborder Brachycera and are relatively large Diptera. Unlike Asilidae, a morphologically and biologically close family, adults of Therevidae are not predatory and lack the deep groove between the eyes characteristic of Asilidae.

In Finland, there has been very little information published on Therevidae. Frey (1911) listed some of the oldest records for the lower Brachyceran flies. In their exchange-score catalogue, Frey et al. (1941) recorded 13 species of Therevidae as being Finnish but using names that are currently invalid. Hackman's (1980) checklist included 20 species of Therevidae.

After the turn of the new millennium, a new wave of dipterological interest has begun in Finland. As large and conspicuous flies, Therevidae can be considered a suitable group for research, but there has been a lack of updated taxonomic information. For example, the Therevidae key for the European part of Russia (Zaitsev 1988) leads to unreliable or inadequate identifications of Finnish Therevidae. Furthermore, a recent British book on lower Brachycera (Stubbs \& Drake 2001) lacks many Finnish species. The most accurate key for determining Finnish Therevidae was presented by Lyneborg and Spitzer (1974); this key covers the Czech Republic fauna.

The purpose of this article is to provide an updated key for the Finnish Therevidae and some species found in the neighbouring countries. The distribution and habitat associations for each species are briefly discussed based on the few available distributional and ecological data. A preliminary understanding of the Finnish Therevidae fauna was obtained during the autumn 2003, the Finnish museum material of Therevidae was checked for a Brachycera checklist (Kahanpää \& Winqvist 2005). Three species listed by Hackman (1980) appeared not to belong to the Finnish fauna: both European Cliorismia species had been recorded In Russian Karelia, and Thereva circumscripta (Loew) is a more southern European species. Now there are 17 species of Therevidae known from Finland.

There remains a lot to be discovered about this elusive fly family. New studies are needed to obtain a more profound understanding of the distri- 

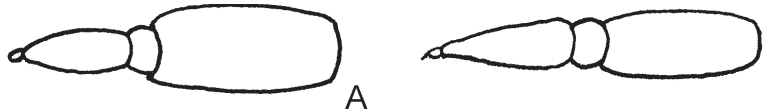

Fig. 1. (A) The antennae of Dialineura anilis and (B) Acrosathe annulata.
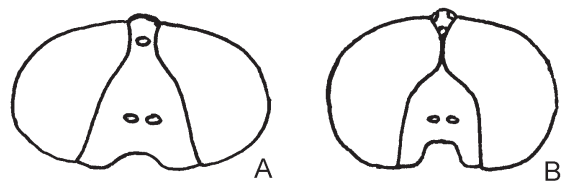

Fig. 3. The head of $(A)$ Dichoglena nigripennis and (B) Psilocephala imberbis males.
B

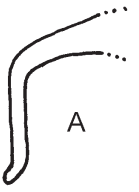

Fig. 4. The tip of aedeagus in lateral view. (A) Cliorismia ardea and (B) Cliorismia rustica males. butions, ecological associations, and conservation status of Therevidae species in Finland.

\section{Key to the Finnish species of Therevidae}

The following key covers all the 17 Finnish Therevidae species and six additional species (listed within brackets) that have been found from Scandinavia, Russia or Baltic countries. This key is based on our studies and literature (Lyneborg \& Spitzer 1974, Stubbs \& Drake 2001, Zaitsev 1988).

1a First segment of antennae thicker than the pedicel and flagellum (Fig. 1A)

\section{Dialineura anilis}

1b All segments of antennae equally thick (Fig. 1B)

2a Face hairy

$2 b$ Face bare

2

3

3a Male: Tergites silvery pollinose and the hairs on abdomen silvery white Female: Frons without callus

3b Male: Tergites without pollen to fully dusted with dirty yellow or grey pollen (usually with a dark anterior and lighter posterior region), hairs on abdomen mixed dark (black to brownish black) and light (yellow to white)
Female: Frons with a continuous or divided shiny black callus (frontal callus) Thereva

4a Knob of halteres light 5

4b Knob of halteres dark Spiriverpa lunulata

5a Male: Middle femora with usually 2 anteroventral bristles (Fig. 2)

Female: Erect hairs on tergites 5-8 black

Acrosathe annulata

5b Male: Middle femora usually without anteroventral bristles

Female: Erect hairs on tergites 5-8 white

[Acrosathe baltica]

6a Males

11

$6 \mathrm{~b}$ Females

7a Frons broader than anterior ocellus (Fig. 3A). Abdomen silvery pollinose or black with silvery pattern

8

$7 \mathrm{~b}$ Frons narrower than anterior ocellus (Fig. 3B). Abdomen silvery pollinose

\section{9}

8a Halteres black. Abdomen silvery pollinose

Dichoglena nigripennis

$8 \mathrm{~b}$ Halteres yellow. Abdomen black, tergites with weak silvery triangles

Pandivirilia eximia

9a Femora completely black from base to apex Psilocephala imberbis

9b Femora with yellow apex

10a Tip of aedeagus straight (Fig. 4A)

[Cliorismia ardea]

10b Tip of aedeagus S-shaped (Fig. 4B)

[Cliorismia rustica] 

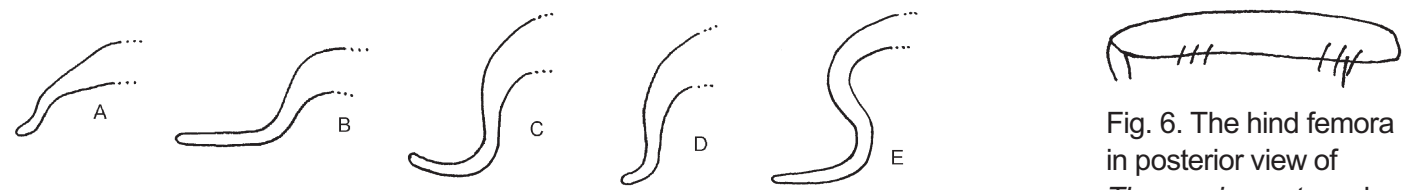

Fig. 6. The hind femora in posterior view of Thereva inornata male.

Fig. 5. The tip of aedeagus in lateral view. (A) Thereva cinifera, (B) $T$. fulva, (C) T. inornata, (D) T. plebeja and (E) T. strigata males.

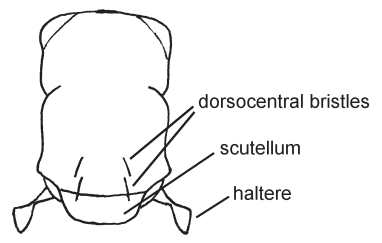

Fig. 7. The mesonotum of Thereva.

11a Femora completely black from base to apex

11b Femora with yellow apex

[C. ardea and C.rustica]

12a Tibiae and tarsi as dark as femora. Wing membrane with brownish border adjacent to wing veins

Dichoglena nigripennis

$12 \mathrm{~b}$ Tibiae and tarsi yellowish, lighter in contrast to femora. Wing membrane without brownish border adjacent to wing veins

13

13a Wing membrane yellow basally. Large species $(12-18 \mathrm{~mm})$

Pandivirilia eximia

$13 \mathrm{~b}$ Wing membrane completely transparent. Small species $(8-10 \mathrm{~mm})$

\section{Psilocephala imberbis}

\section{Genus Thereva}

1a Males

1b Females

2a All tergites light anteriorly, tergites completely dusted with dirty yellow or grey pollen

2b Anterior region of at least tergites 2-5 dark 4

3a Knob of halteres brownish black. Tip of aedeagus short(Fig. 5A) T. cinifera

$3 \mathrm{~b}$ Knob of halteres yellowish brown. Tip of aedeagus long (Fig. 5B)

4a All tergites glossy black

$4 \mathrm{~b}$ At least part of the tergites matt

[T. fulva]

[T. atripes]

5a At least one posteroventral bristle in the basal part of the hind femora (Fig. 6)
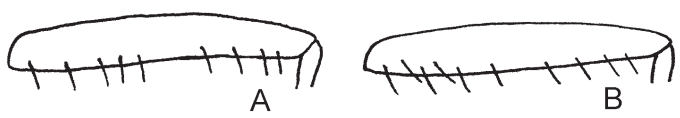

Fig. 8. The hind femora in anterior view of (A) Thereva inornata and (B) T. nobilitata males.

$5 \mathrm{~b}$ The basal part of hind femora without posteroventral bristles

6a 2 pairs of dorsocentral bristles (Fig. 6). The basal part of hind femora with 3-4 posteroventral bristles (Fig. 7). The anteroventral bristles of the hind femora usually uniserial (Fig. 8A). Tip of aedeagus long curved (Fig. 5C)

T. inornata

6b 1 pair of dorsocentral bristles. The basal part of hind femora with 1-3 posteroventral bristles. Hind femora with additional bristles outside the normal anteroventral row (as in Fig. 8B)

7a Anterior part of tergites 4-5 with narrow dark band (more than half the lateral part of tergites 4-5 dusted with grey pollen) 8

$7 \mathrm{~b}$ Anterior part of tergites 4-5 with broad dark band (only half the lateral part of tergites 4-5 dusted with grey pollen)

8a Tergite 6 fully dusted with greyish pollen (dark anterior transverse band absent). Wing membrane greyish, veins light brown and crossveins weakly darkened. Hairs on the lower part of the occiput and parafacial mixed with white and black T. unica

8 b Tergite 6 incompletely dusted with greyish pollen (dark anterior transverse band present). Wing membrane whitish, veins dark brown and crossveins intensively darkened. Hairs on the lower part of the occiput and parafacial white

[T. marginula $]$

9a Mesonotum greyish brown and usually with 
a clear dark brown central line. Hairs on tergite 1 completely black or dark brown. Tip of aedeagus short (Fig. 5D)

T. plebeja

9b Mesonotum bluish gray and at most with a diffuse dark central line. Hairs on tergite 1 grey or yellowish medially. Tip of aedeagus long (Fig. 5E)

T. strigata

10a Hairs on scutellum sparse and completely black. Hairs on abdomen predominantly black. Usually 1 dorsocentral bristle. Front femora anteroventrally usually without bristles

T. valida

10b Hairs on scutellum mixed yellow and black. Hairs on abdomen yellow laterally and black dorsally

10c Hairs on scutellum and abdomen almost completely white

11a Anteroventral bristles of the hind femora multiserial (some bristles outside the normal anteroventral row) (Fig. 8B). Hairs on scutellum not exceptionally dense and mixed yellowish and black. Usually 1 dorsocentral bristle. Front femora with 1-4 anteroventral bristles

T. nobilitata

11b Anteroventral bristles of hind femora uniserial (as in Fig. 8A). Hairs on scutellum dense and almost completely yellow. 2 dorsocentral bristles. Front femora with 2-7 anteroventral bristles

T. handlirschi

12a 2-3 pairs of dorsocentral bristles (Fig. 7). Wing veins narrowly bordered by dark membrane. Front femora without anteroventral bristles. Mesonotum with indistinct longitudinal stripes T. fuscinervis

12b 1 pair of dorsocentral bristles. Wing veins not bordered by dark membrane. Front femora with or without anteroventral bristles. Mesonotum with distinct or indistinct longitudinal stripes

13

13a Front tibia longer than front femora. Head (in dorsal view) as broad as mesonotum. Front femora with anteroventral bristles. Mesonotum with distinct light longitudinal stripes

T. microcephala

13b Front tibia as long as front femora. Head (in dorsal view) broader than mesonotum. Front femora without anteroventral bristles. Mesonotum with indistinct light longitudinal stripes

T. lanata

14a Shiny black frontal callus forming one nar- row transverse band or divided into two separate calli 15

14b One wide, usually large, shiny black frontal callus

15a Frontal callus a narrow transverse band that is sometimes divided medially (Fig. 9A). Anteroventral bristles of the hind femora uniserial (as in Fig. 8A) T. valida

$15 \mathrm{~b}$ Frontal callus clearly separated on two parts (Fig. 9B). Anteroventral bristles of the hind femora nearly uniserial, but irregularly arranged towards base (as in Fig. 8B)

T. unica

16a All tergites light anteriorly, tergites completely dusted with dirty yellow or grey pollen

$16 \mathrm{~b}$ Anterior region of at least tergites $2-5$ dark 18

17a Knob of halteres blackish. Tergite 7 dusted with grey pollen. The frontal callus separated from the anterior ocellus (Fig. 9C)

T. cinifera

17b Knob of halteres yellowish. Tergite 7 glossy black and only laterally grey pollinose. The frontal callus extends to the anterior ocellus (Fig. 9D)

[T. fulva]

18a The frontal callus extends dorsally around the ocellar tubercle (Fig. 9E)

$18 \mathrm{~b}$ The frontal callus extends dorsally at most to the anterior ocellus

19a Tibiae black. Wing membrane dark

[T. atripes]

19b Tibiae yellowish. Wing membrane with dark areas only adjacent to wing veins, predominantly clear to translucent whitish grey 20

20a 2-3 dorsocentral bristles (Fig. 7). Wing veins narrowly bordered by dark membrane. Frons and frontal callus narrower than in $T$. lanata

T. fuscinervis

20b 1 dorsocentral bristle. Wing veins not bordered by dark membrane. Frons and frontal callus wider than in T. fuscinervis (Fig. 9E)

T. lanata

21a Anterior part of tergites 2-5 with dark band extending medially to posterior edge (posterior of tergites 2-4 with broken or nearly broken band of grey pollen). Frontal callus in Fig. 9F

T. microcephala

$21 \mathrm{~b}$ Anterior part of tergites $2-5$ with dark band extending medially near to posterior edge 

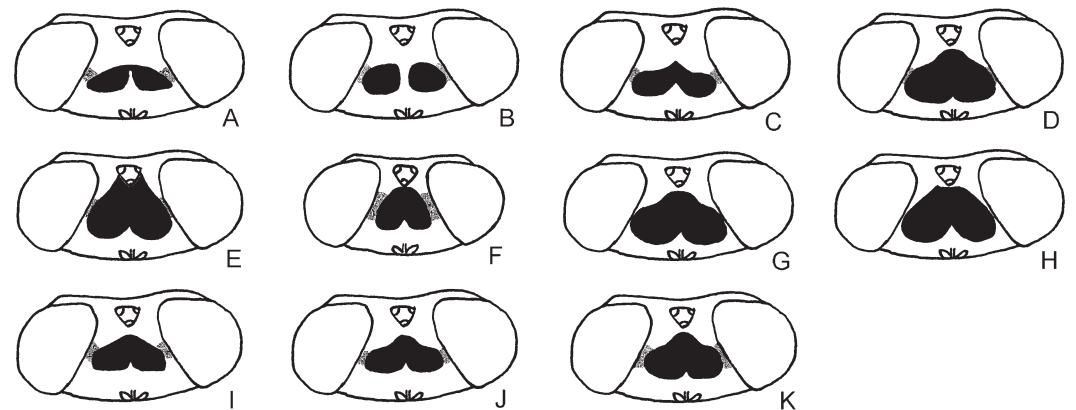

Fig. 9. The frontal callus of (A) Thereva valida, (B) T. unica, (C) T. cinifera, (D) T. fulva, (E) T. lanata, (F) T. microcephala, (G) $T$. plebeja, (H) T. strigata, (I) T. nobilitata, (J) T. inornata and $(\mathrm{K}) T$. handlirschi females.
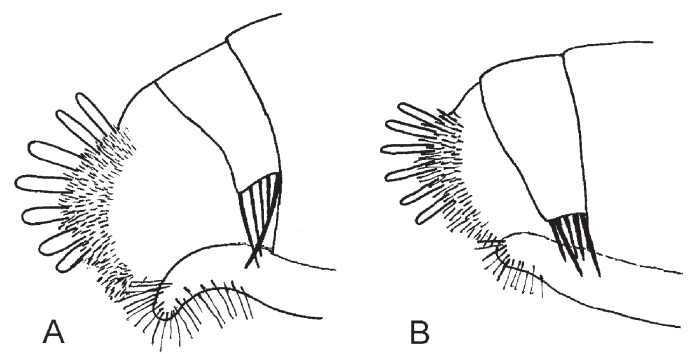

(posterior of tergites 2-4 with complete band of grey pollen)

22a Frontal callus extends laterally to eye margin

22b Frontal callus separated from eye margin by a matt area

23a Spines on the tip of ovipositor broad and blunt (Fig. 10A). Mesonotum dark, brownish grey with distinct light longitudinal stripes. Frontal callus in Fig. 9G T. plebeja

$23 \mathrm{~b}$ Spines on the tip of ovipositor slender (Fig. 10B). Mesonotum light, bluish grey with distinct light longitudinal stripes. Frontal callus in Fig. 9H

T. strigata

24a Knob of halteres yellowish brown. Anteroventral bristles of the hind femora multiserial (some bristles outside the normal anteroventral row) (as in Fig. 8B). Frontal callus separated from anterior ocellus (Fig. 9I). Wing membrane greyish brown, veins light brown and crossveins not bordered by dark membrane. Tergite 3 without contrasting line between anterior narrow dark brownish part and posterior greyish part of the tergite

T. nobilitata

24b Knob of halteres blackish. Anteroventral bristles of the hind femora multiserial (some bristles outside the normal anteroventral
Fig. 10. The tip of ovipositor in posterolateral view (A) Thereva plebeja and (B) $T$. strigata females. row) (as in Fig. 8B). Frontal callus narrowly separated from anterior ocellus. Wing membrane whitish, veins dark brown and crossveins bordered by dark membrane. Tergite 3 without contrasting line between anterior dark brownish part and posterior greyish part of the tergite

[T. marginula $]$

24c Knob of halteres blackish. Anteroventral bristles of hind femora uniserial (as in Fig. $8 \mathrm{~A}$ ). Frontal callus separated from or extends to anterior ocellus. Wing membrane greyish brown, veins light brown and crossveins not bordered by dark membrane. Tergite 3 with contrasting line between anterior broad blackish part and posterior greyish part of the tergite

25a Hairs on scutellum mixed black and yellowish. Frontal callus separated from the anterior ocellus (Fig. 9J)

T. inornata

25b Hairs on scutellum yellow. Frontal callus extends to the anterior ocellus (Fig. 9K)

T. handlirschi

\section{Faunistic comments and the evaluation of threatened species}

The following faunistic comments are based on checking the Finnish museum collections (Finn- 


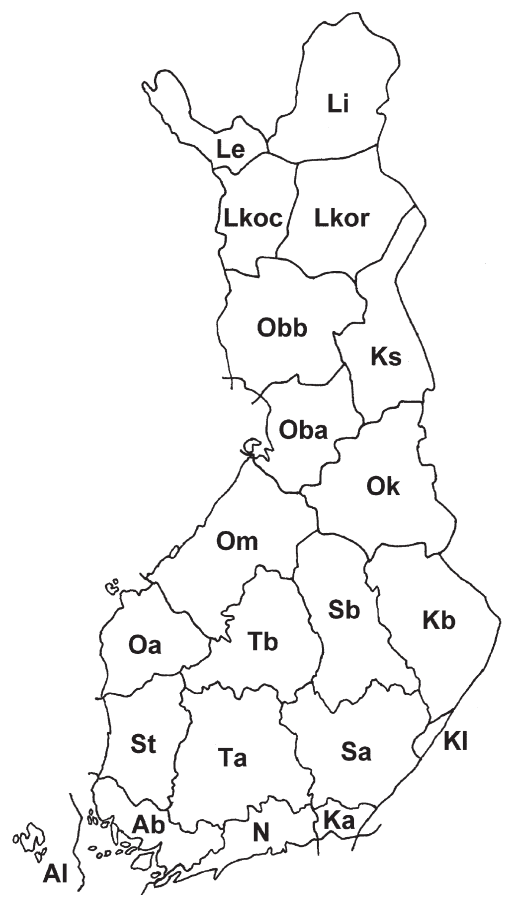

Fig. 11. The Finnish biogeographical provinces and their codes. $\mathrm{Al}=$ Alandia, $\mathrm{Ab}=$ Regio aboensis, $\mathrm{N}=$ Nylandia, $\mathrm{Ka}$ $=$ Karelia australis, $\mathrm{St}=$ Satakunda, $\mathrm{Ta}$ = Tavastia australis, $\mathrm{Sa}=$ Savonia australis, $\mathrm{KI}=$ Karelia ladogensis, $\mathrm{Oa}=$ Ostrobottnia australis, $\mathrm{Tb}=$ Tavastia borealis, $\mathrm{Sb}=$ Savonia borealis, $\mathrm{Kb}=$ Karelia borealis, Om = Ostrobottnia me$\mathrm{dia}, \mathrm{Ok}=$ Ostrobottnia kajanensis, Oba $=$ Ostrobottnia borealis pars australis, $\mathrm{Obb}=$ Ostrobottnia borealis pars borealis, Ks = Regio kuusamoensis, Lkoc = Lapponia kemensis pars occidentalis, Lkor $=$ Lapponia kemensis pars orientalis, Le = Lapponia enontekiensis, $\mathrm{Li}=$ Lapponia inarensis.

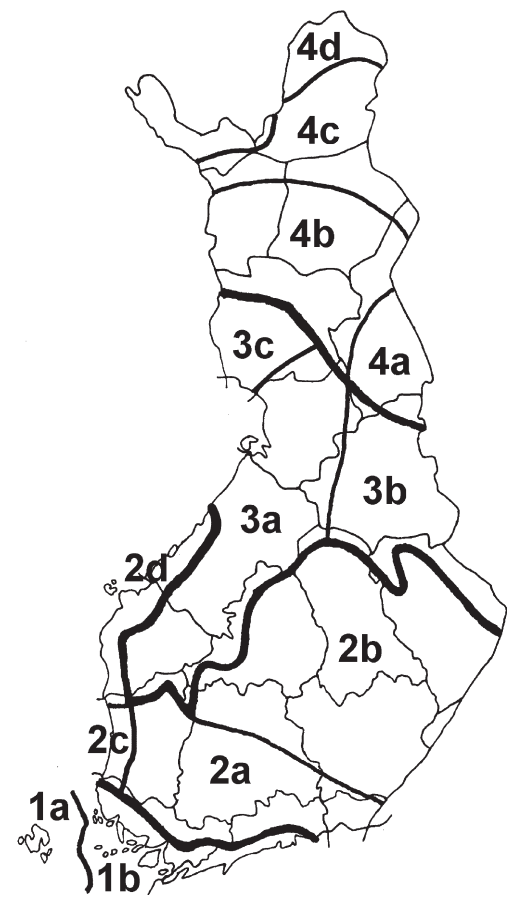

Fig. 13. The map with Finnish vegetation zones. (1a) Hemiboreal, Åland Islands, (1b) Hemiboreal, Southwestern coast, (2a) Southern boreal, Southwestern district, (2b) Southern boreal, Finnish lake district, (2c) Southern boreal, Coast of Satakunda, (2d) Southern boreal, Coast of Ostrobothnia, (3a) Middle boreal, Ostrobothnia, (3b) Middle boreal, Kainuu district, (3c) Middle boreal, Triangle of Lapland, (4a) Northern boreal, Koillismaa district, (4b) Northern boreal, Southern Lapland, (4c) Northern boreal, Forest Lapland and (4d) Northern boreal, Mountain Lapland.

Table 1. The category in the evaluation of threatened species and the corresponding number of known locations, following Rassi et al. (2001).

\section{Category}

Meaning
Number of population locations

CR Critically endangered
EN Endangered
VU Vulnerable
NT Near threatened
LC Least concern

CR Critically endangered

Extremely high risk of extinction in the wild Very high risk of extinction in the wild High risk of extinction in the wild Close to qualifying for or near to become vulnerable Common and abundant or has steady populations 

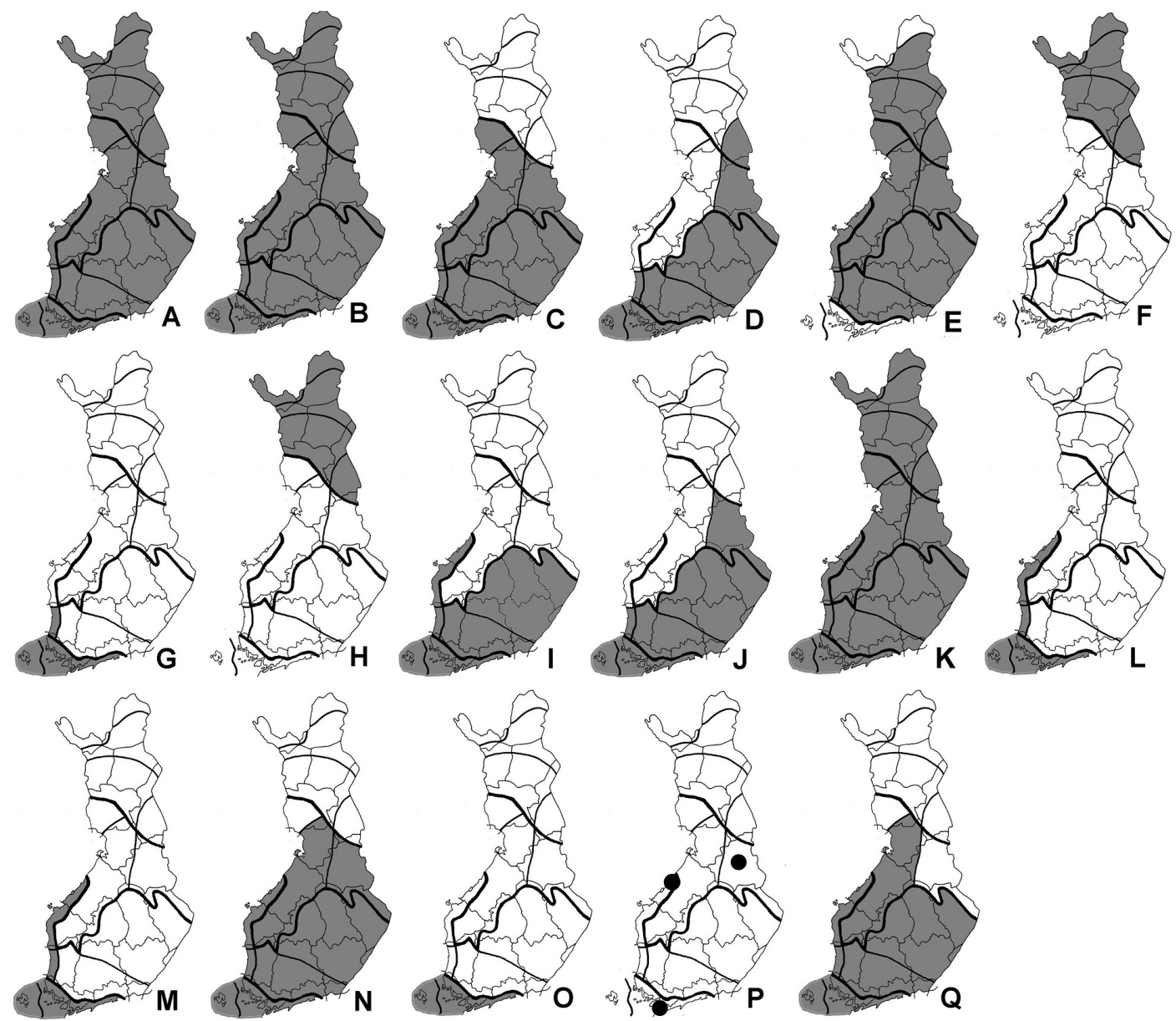

Fig. 12. Distribution maps of the Finnish species (A) A. annulata, (B) D. anilis, (C) D. nigripennis, (D) P. eximia, (E) P. imberbis, (F) S. lunulata, (G) T. cinifera, (H) T. fuscinervis, (I) T. handlirschi, (J) T. inornata, (K) T. lanata, (L) T. microcephala, (M) T. nobilitata, (N) T. plebeja, (O) T. strigata, $(\mathrm{P})$ T. unica and $(\mathrm{Q})$ T. valida.

ish Museum of Natural History in Helsinki (FMNH), Zoological Museum of University of Turku (MZT), Natural History Museum of Forssa, Natural History Section of Museum of Kuopio and Zoological Museum of University of Oulu) as well as numerous private collections. Therevidae specimens collected during various entomological projects have been identified and used in these evaluations.

After the faunistic text for each species, we categorize each species based on evaluation criteria for threatened species approved by the World Conservation Union in 1994 (Rassi et. al. 2001) and list geographical provinces from which each species has been recorded (Fig. 11). The most frequently used category for Finnish Therevidae species, and many other insects, is criterion $\mathrm{D}$, or "population restricted". Criterion D is, however, a common category because limited resources are available in Finland to monitor populations of threatened insect species. Because collecting activities in Finland were relatively infrequent until the turn of the century, lower categories are also preferred for species represented by few specimens in collections. Category A, "reduction of population size," is used for one species: Thereva strigata. The categories in the evaluation of threatened species are shown in Table 1. Species distributions (Fig. 12) were estimated using locality records and distributions of Finnish vegetation zones (Fig. 13). 
Acrosathe annulata (Fabricius, 1805)

A species commonly found on dunes and in other sandy biotopes throughout the country. This species is assessed to the category LC and does not need monitoring. $\mathrm{Al}, \mathrm{Ab}, \mathrm{N}, \mathrm{Ka}, \mathrm{St}, \mathrm{Ta}, \mathrm{Sa}, \mathrm{Kl}, \mathrm{Oa}$, $\mathrm{Tb}, \mathrm{Sb}, \mathrm{Kb}, \mathrm{Om}, \mathrm{Ok}, \mathrm{Oba}, \mathrm{Obb}, \mathrm{Ks}, \mathrm{Lkoc}, \mathrm{Li}$.

\section{[Acrosathe baltica Andersson, 1994]}

This recently described species is found from the Baltic Islands in Sweden. It is possible to find $A$. baltica on dunes from the south coast of Finland. The male of $A$. baltica can be reliably differentiated from $A$. annulata only by genitalic features. (Andersson 1994).

\section{[Cliorismia ardea (Fabricius, 1794)]}

The only specimens have been recorded from Karelia, Russia. C. ardea is thus deleted from the Finnish checklist. It is possible to find C. ardea from sandy riverbanks in southeastern Finland near the Russian border.

\section{[Cliorismia rustica (Panzer, 1803)]}

The only specimens have been recorded from Karelia, Russia. C. rustica is thus deleted from the Finnish checklist. Also this species can be found from sandy riverbanks in southeastern Finland near the Russian border.

Dialineura anilis (Linnaeus, 1761)

A species commonly found on dunes and in other sandy biotopes throughout the country. This species is assessed to the category LC and does not need monitoring. $\mathrm{Al}, \mathrm{Ab}, \mathrm{N}, \mathrm{St}, \mathrm{Ta}, \mathrm{Sa}, \mathrm{Kl}, \mathrm{Oa}, \mathrm{Tb}$, $\mathrm{Sb}, \mathrm{Kb}, \mathrm{Om}, \mathrm{Ok}, \mathrm{Obb}, \mathrm{Ks}, \mathrm{Lkoc}, \mathrm{Lkor}, \mathrm{Li}$.

\section{Dichoglena nigripennis (Ruthe, 1831)}

A rare species of which only seven scattered records from various parts of the country are known. Since there is only one record made in the recent years, Ok: Sotkamo (Söderman \& Leinonen 2003), the species is assessed to the category EN and the known population and the possible new findings will need active monitoring. $\mathrm{Al}$, $A b, N, S t, K b, O k, O b a$.

\section{Pandivirilia eximia (Meigen, 1820)}

A rather common species found mostly in moist meadows in the southern and central Finland, the most northern locality being Kuusamo. Females are more commonly found than males. This species is assessed to the category LC and does not need monitoring. Ab, $N, \mathrm{Ka}, \mathrm{St}, \mathrm{Ta}, \mathrm{Sa}, \mathrm{Kl}, \mathrm{Tb}, \mathrm{Sb}$, Ks.

\section{Psilocephala imberbis (Fallén, 1814)}

A species historically distributed evenly almost throughout the country, but the records of which are predominantly old. Since there are only three records made in the latest 30 years, $\mathrm{Ta}$ : Tammela (Mattila 1998), Ta: Ylöjärvi (Mattila 2001) and Ta: Lammi (Ahlroth 2002), the species is assessed to the category VU and the last known populations and the possible new findings will need monitoring. $\mathrm{Ab}, \mathrm{N}, \mathrm{St}, \mathrm{Ta}, \mathrm{Sa}, \mathrm{Kl}, \mathrm{Oa}, \mathrm{Tb}, \mathrm{Sb}$, $\mathrm{Kb}, \mathrm{Om}, \mathrm{Ok}, \mathrm{Oba}, \mathrm{Li}$.

\section{Spiriverpa lunulata (Zetterstedt, 1838)}

At least predominantly a northern species found in sandy biotopes. The few Finnish museum specimens of this species had been loaned by Donald Webb, who reported $S$. lunulata from the provinces $K s-L i$ in a letter. He also reported an older record from $N$ : Lappohja, which could be a labelling mistake. There are only two new records of this species, Li: Utsjoki (Haarto 1994) and Lkor: Savukoski (Bagge 2003), but the collecting activity has been low in northern Finland. This species is assessed to the category VU and does not need active monitoring. $(N) K s,, L k o r$, Li.

\section{[Thereva atripes (Loew, 1847)]}

An eastern species distributed from the southern Siberia to the St. Petersburg area (Zaitsev 1988). It might be possible to find $T$. atripes from the southeastern Finland near the Russian border.

\section{Thereva cinifera (Meigen, 1830)}

In addition to the old known population, there are three new populations of this scarce species found, $A b$ : Dragsfjärd (Clayhills et al. 1996), $N$ : Hanko (Haarto 1996) and $N$ : Helsinki (Kahanpää 2003). All these localities are from the southwestern coast. This species is probably connected with the Baltic sandy shores in Finland. It is assessed to the category VU and needs monitoring. Ab, N, St. 
[Thereva circumscripta Loew, 1847]

The specimens determined as $T$. circumscripta turned out to belong to the species T. valida Loew. T. circumscripta is thus deleted from the Finnish checklist.

\section{[Thereva fulva Meigen, 1804]}

There was one specimen misidentified as T. fulva in the collection of FMNH. This is a Central European species distributed north to the St. Petersburg area (Zaitsev 1988). It might be possible to find T. fulva from the south coast of Finland.

\section{Thereva fuscinervis Zetterstedt, 1838}

A rather commonly found species predominantly in the northern Finland, but there are two specimens from $A b$ in the MZT, which were collected by Lahtiperä in the 1950's. These southern records are probably labelling mistakes. This species is assessed to the category LC and does not need monitoring. ( $\mathrm{Ab}$, ) Obb, Ks, Lkoc, Le, $\mathrm{Li}$.

\section{Thereva handlirschi Kroeber, 1912}

One of the commonest species of the genus distributed in the southern Finland. This species is assessed to the category LC and does not need monitoring. Al, Ab, N, Ka, St, Ta, Sa, Oa.

\section{Thereva inornata Verrall, 1909}

A rather common species in the southern and central Finland, but may be commonest in the east. This species occurs mainly in sandy biotopes. This species is assessed to the category LC and does not need monitoring. $\mathrm{Al}, \mathrm{Ab}, \mathrm{N}, \mathrm{St}, \mathrm{Ta}, \mathrm{Sa}, \mathrm{Kl}$, $\mathrm{Tb}, \mathrm{Sb}, \mathrm{Kb}, \mathrm{Ok}$.

\section{Thereva lanata Zetterstedt, 1838}

One of the commonest species of the genus in Finland distributed especially abundant in the north. This species occurs mainly in sandy biotopes. This species is assessed to the category LC and does not need monitoring. $A b, N, K a, T a$, $\mathrm{Sa}, \mathrm{Kl}, \mathrm{Tb}, \mathrm{Sb}, \mathrm{Kb}, \mathrm{Om}, \mathrm{Ok}, \mathrm{Oba}, \mathrm{Obb}, \mathrm{Ks}, \mathrm{Lkoc}$, Lkor, Le, Li.

\section{[Thereva marginula Meigen, 1820]}

A South and Central European species distributed north to the southern Sweden. It might be possible to find T. marginula from the south coast of Finland.
Thereva microcephala (Loew, 1847)

This species is distributed along the coast. T. microcephala is found in forests in the Central Europe (Keil 2003) and also in Finland the new records of this species have been made in moist forests. Despite the few records made, the species might thus be less vulnerable than many other species in the genus. This species is assessed to the category NT and does not need monitoring. $A l, A b, N, O m$.

\section{Thereva nobilitata (Fabricius, 1775)}

A species historically thought to be common in Finland (Frey 1911) but it has often been mixed with $T$. handlirschi (Kroeber). There are only four certain records from Finland, all from dry or sandy biotopes near the coast: Al: Kökar (Hellén), $A b$ : Korppoo (Panelius 1961), $A b$ : Dragsfjärd (Haarto 1994), Om: Lohtaja (Ahola 2004). This species is assessed to the category VU. The last known populations and the possible new findings will need monitoring. $\mathrm{Al}, \mathrm{Ab}, \mathrm{Om}$.

Thereva plebeja (Linnaeus, 1758)

A dark Thereva species distributed evenly and commonly in the southern and central parts of Finland. This species is assessed to the category LC and does not need monitoring. $A l, A b, N, K a$, $\mathrm{St}, \mathrm{Ta}, \mathrm{Sa}, \mathrm{Kl}, \mathrm{Oa}, \mathrm{Tb}, \mathrm{Om}, \mathrm{Ok}$.

\section{Thereva strigata (Fabricius, 1794)}

A very rare species connected with sandy biotopes and known only from the south. There are no records of this species after the year 1943. It is possible that $T$. strigata is actually extinct from Finland, but because of the limited collection activity it might be overlooked. At this stage it is assessed to the category CR. If a population of T. strigata is found again from Finland, then the population will need active monitoring. $\mathrm{Al}$, $A b, N$.

\section{Thereva unica (Harris, 1780)}

In addition to the old known population in Hanko area, $N$ : Tvärminne, there are two new populations found, Ok: Sotkamo (Söderman \& Leinonen 2004) and Om: Raahe (Varpenius 2004). This species might be connected with dry heath forests and sandy biotopes. T. unica is assessed to the category VU and the last known populations 
and the possible new findings will need monitoring. $\mathrm{N}, \mathrm{Om}, \mathrm{Ok}$.

\section{Thereva valida Loew, 1847}

This is a rather common species in the southern and central Finland. This species is assessed to the category LC and does not need monitoring. $\mathrm{Al}, \mathrm{Ab}, \mathrm{N}, \mathrm{St}, \mathrm{Ta}, \mathrm{Sa}, \mathrm{Kl}, \mathrm{Kb}, \mathrm{Om}, \mathrm{Oba}$.

Acknowledgements. We are grateful to Kevin Holston for advice and help in formulating the language of the key and assessing the biological status of Therevidae species. We also thank The Finnish Environment Institute for financing this study in the autumns 2002-2004.

\section{References}

Andersson, H. 1994: A new species of Acrosathe (Diptera: Therevidae) from the Baltic Islands. - Stobaeana 2: $1-6$.

Frey, R. 1911: Zur kenntnis der dipterenfauna Finlands. Acta Societatis pro Fauna et Flora Fennica 34: 6.

Frey, R., Storå, R. \& Tiensuu, L. 1941: Enumeratio Insec- torum Fenniae, VI, Diptera. - Helsingin Hyönteisvaihtoyhdistys: 1-63.

Hackman, W. 1980: A check list of the Finnish Diptera I. Nematocera and Brachycera (s.str.). - Notulae Entomologicae 60: 17-48.

Kahanpää, J, \& Winqvist, K. 2005: Check-list of Finnish flies: families Xylophagidae-Microphoridae. — Sahlbergia 10(1): 10-27.

Keil, P. 2003: Habitat and microhabitat preferences of mountain Therevidae (Diptera) and ecological outline of Czech Therevidae. - BSc thesis, University of South Bohemia.

Lyneborg, L. \& Spitzer, K. 1974: The Czechoslovak species of Thereva Latr. (Therevidae, Diptera) with the description of a new species from Hungary and Austria. - Acta Sci. Nat. Mus. Bohem. Merid. 14: 13-42.

Rassi, P., Alanen, A., Kanerva, T. \& Mannerkoski, I. (eds.) 2001: Suomen lajien uhanalaisuus 2000. — The Finnish Ministry of Environment and the Finnish Environment Institute, Helsinki.

Stubbs, A. \& Drake, M. 2001: British soldierflies and their allies. - British Entomological and Natural History Society. Pp. 512.

Zaitsev, V. F. \& Bei-Bienko, G. Ya. (ed.) 1988: Keys to the Insects of the European part of the USSR, Volume V, Diptera and Siphonaptera, Part I. - Smithsonian Institution Libraries and The National Science Foundation, Washington, D. C. 